\title{
UPAYA MENINGKATKAN HASIL BELAJAR IPA PADA MATERI KLASIFIKASI MAHKLUK HIDUP DENGAN MODEL PEMBELAJARAN PROBLEM BASED LEARNING (PBL) DI KELAS VII SMP NEGERI 1 STABAT
}

\author{
Linda Sari \\ Guru IPA SMP Negeri 1 Stabat \\ Jl. Zaunul Arifin No.10, Kwala Bingai, Kab. Langkat, Sumatera Utara 20811 \\ E-mail: linda.sari.mpd@gmail.com
}

\begin{abstract}
Abstrak
Tujuan penelitian ini adalah: 1) Mengetahui cara peningkatan hasil belajar IPA pada materi klasifikasi mahkluk hidup dengan model pembelajaran problem based learning (PBL) di kelas VII SMP Negeri 1 Stabat Kab. Langkat T.P. 2017/2018; 2) Mengetahui peningkatan hasil belajar IPA pada materi klasifikasi mahkluk hidup di kelas VII SMP Negeri 1 Stabat Kab. Langkat T.P. 2017/2018. Penelitian ini dilaksanakan dalam kelas meliputi kegiatan pelaksanaan tindakan kelas (PTK) berupa kegiatan refleksi awal dan melakukan observasi untuk mengidentifikasi permasalahan yang terjadi di kelas, perencanaan pembelajaran, pelaksanaan tindakan, observasi dan refleksi. Adapun temuan penelitian PTK ini adalah: 1) Pada Siklus I penerapan model pembelajaran Problem Based Learning (PBL) memperoleh hasil belajar dari 32 orang siswa diperoleh 23 orang yang tuntas dengan $72 \%$ dan 9 orang yang tidak tuntas dengan 28\%; 2) Pada Siklus II diperoleh hasil belajar dari 32 orang siswa diperoleh 28 orang yang tuntas dengan $88 \%$ dan 4 orang yang tidak tuntas dengan $12 \%$. Dapat disimpulkan penerapan model pembelajaran problem based learning dapat meningkatkan hasil belajar IPA siswa kelas VII SMP Negeri 1 Stabat Kab. Langkat TP. 2017/2018.
\end{abstract}

Kata Kunci: Model Pembelajaran, Problem Based Learning (PBL), IPA

\begin{abstract}
The objectives of this study were: 1) To find out how to improve science learning outcomes in the classification material of living things with problem-based learning (PBL) learning models in class VII of SMP Negeri 1 Stabat, Kab. Langkat T.P. 2017/2018; 2) Knowing the improvement of science learning outcomes in the material classification of living things in class VII of SMP Negeri 1 Stabat, Kab. Langkat T.P. 2017/2018. This research was carried out in the classroom covering classroom action activities (PTK) in the form of initial reflection activities and conducting observations to identify problems that occur in the classroom, planning learning, implementing actions, observation and reflection. The PTK research findings are: 1) In the first cycle the application of the Problem Based Learning (PBL) learning model obtained learning outcomes from 32 students obtained 23 people who completed $72 \%$ and 9 people who did not complete with $28 \%$; 2) In Cycle II learning outcomes obtained from 32 students obtained 28 people who completed $88 \%$ and 4 people who did not complete with $12 \%$. It can be concluded that the application of problem based learning learning models can improve science learning outcomes of class VII students SMP Negeri 1 Kab. Langkat TP. 2017/2018.
\end{abstract}

Keywords : Learning Models, Problem Based Learning, IPA

\section{PENDAHULUAN}

Pendidikan merupakan bagian terpenting dalam pembangunan nasional. Pendidikan di artikan sebagai upaya meningkatkan harkat dan martabat manusia serta di tuntut untuk menghasilkan manusia yang berkualitas guna menjamin pelaksanaan dan kelangsungan pembangunan.

Peningkatan hasil belajar khususnya di Sekolah Menengah Pertama (SMP) tidak akan terjadi tanpa adanya kerjasama dari berbagai pihak. Pendidikan dan pengajaran dapat berhasil sesuai 
dengan harapan dipengaruhi oleh faktor-faktor yang saling berkaitan dan saling menunjang. Faktor yang paling menentukan keberhasilan pendidikan/pengajaran adalah guru, sehingga guru sangat dituntut kemampuannya untuk menyampaikan bahan pengajaran kepada siswa dengan baik, untuk itu guru perlu mendapatkan pengetahuan tentang metode dan media pengajaran yang dapat di gunakan dalam proses belajar mengajar.

Pendidikan IPA menekankan pada pemberian pengalaman langsung untuk mengembangkan kompetensi agar peserta didik menjelajahi dan memahami alam sekitar secara ilmiah. Pendidikan IPA diarahkan untuk mencari tahu dan berbuat sehingga dapat membantu peserta didik untuk memperoleh pemahaman yang lebih mendalam tentang dirinya sendiri dan alam sekitar.

Biologi sebagai salah satu bidang IPA menyediakan berbagai pengalaman belajar untuk memahami konsep dan proses sains. Keterampilan proses ini meliputi keterampilan mengamati, mengajukan hipotesis, menggunakan alat dan bahan secara baik dan benar dengan selalu mempertimbangkan keamanan dan keselamatan kerja, mengajukan pertanyaan, menggolongkan dan menafsirkan data, serta mengkomunikasikan hasil temuan secara lisan atau tertulis, menggali dan memilah informasi faktual yang relevan untuk menguji gagasan-gagasan atau memecahkan masalah sehari-hari.

Mata pelajaran Biologi dikembangkan melalui kemampuan berpikir analitis, induktif, dan deduktif untuk menyelesaikan masalah yang berkaitan dengan peristiwa alam sekitar. Penyelesaian masalah yang bersifat kualitatif dan kuantitatif dilakukan dengan menggunakan pemahaman dalam bidang matematika, fisika, kimia dan pengetahuan pendukung lainnya.

Proses pembelajaran yang di lakukan selama ini di SMP Negeri 1 Stabat Khususnya Kelas VII, cenderung pada pencapaian target materi kurikulum dan lebih mementingkan pada penghafalan konsep bukan pada pemahaman. Guru menyampaikan materi dengan metode ceramah, dimana siswa hanya duduk, mencatat dan mendengarkan apa yang akan di sampaikan, sehingga ketika di minta untuk bertanya oleh guru, banyak yang tidak melakukannya. Siswa kurang termotivasi untuk lebih aktif mengutarakan pendapat, ide gagasan, pertanyaan, dan kesulitan kesulitan maupun hal-hal yang belum di pahami selama pelajaran berlangsung. Suasana pembelajaran biologi masih sangat kurang sehingga proses dan hasil belajar juga sangat rendah. Hasil ulangan harian yang dilakukan diawal semester menunjukkan sekitar $70 \%$ siswa tidak tuntas belajar.

Kondisi tersebut membuat guru, melakukan evaluasi diri melalui refleksi dan diskusi dengan teman sejawat hasil diskusi tersebut teman sejawat ada yang berpendapat bawah hendaknya pembelajaran yang dilakukan sebaiknya menggunakan strategi pembelajaran yang mengajak siswa untuk secara aktif menemukan fakta, konsep, prinsip dengan melalui suatu proses sehingga siswa akan memperoleh pengalaman belajar yang mendalam. Selain itu penggunaan media yang nyata, menarik dan dapat diobservasi secara langsung oleh siswa juga harus dilakukan. Pembelajaran dapat dilaksanakan tidak hanya di dalam kelas tanpa menghadirkan media yang menarik bagi siswa, namun pembelajaran dapat pula dilaksanakan di luar kelas dengan memanfaatnya lingkungan sebagai media dan sumber belajarnya.

Berdasarkan refleksi dan diskusi dengan teman sejawat tentang proses pembelajaran IPA penelitian akan menerapkan model pembelajaran Problem Based Learning (PBL). Model PBL merupakan salah satu model pembelajaran yang dapat memacu siswa belajar melalui upaya penyelesaian masalah yang ada pada dunia nyata secara terstruktur untuk mengkonstruksi pengetahuan siswa. Dengan kata lain, pembelajaran ini akan dapat membentuk kemampuan berpikir tingkat tinggi pada siswa (Abdullah, Sani Ridwan, 2014).

Model problem based learning memiliki pengaruh yang signifikan terhadap hasil belajar biologi dibandingkan metode konvensional, karena model ini dapat merangsang kemampuan siswa untuk menemukan pengetahuan atau ide baru. Secara garis besar model pembelajaran ini dapat menumbuhkan keaktifan dan kemandirian siswa dalam proses pembelajaran terutama dalam pemecahan suatu masalah yang terkait dengan kegiatan dan materi pembelajaran yang sedang berlangsung. Selain itu, dalam model pembelajaran berbasis masalah ini siswa akan dihadapkan pada suatu masalah dalam dunia nyata yang ditemukan dalam kehidupan seharihari dan siswa tersebut dituntut untuk dapat mencari solusi atau pemecahan masalah tersebut (Prihatini, 2015). 
Melalui laporan Penelitian Tindakan Kelas (PTK) ini penulis melakukan penelitian perbaikan pembelajaran di SMP Negeri 1 Stabat. Pada mata pelajaran IPA yang berjudul "Upaya Meningkatkan Hasil Belajar IPA Pada Materi Klasifikasi Mahkluk Hidup dengan Model Pembelajaran Problem Based Learning (PBL) Di Kelas VII SMP Negeri 1 Stabat Kab. Langkat T.P. 2017/2018".

Berdasarkan Rumusan masalah di atas, adapun tujuan dari penelitian tindakan kelas ini adalah: 1) Mengetahui cara peningkatan hasil belajar IPA pada materi klasifikasi mahkluk hidup dengan model pembelajaran problem based learning (PBL) di kelas VII SMP Negeri 1 Stabat Kab. Langkat T.P. 2017/2018; 2) Mengetahui peningkatan hasil belajar IPA pada materi klasifikasi mahkluk hidup di kelas VII SMP Negeri 1 Stabat Kab. Langkat T.P. 2017/2018.

\section{METODE PENELITIAN}

Penelitian ini dilaksanakan dalam kelas meliputi kegiatan pelaksanaan tindakan kelas (PTK) berupa kegiatan refleksi awal dan melakukan observasi untuk mengidentifikasi permasalahan yang terjadi di kelas, perencanaan pembelajaran, pelaksanaan tindakan, observasi dan refleksi. Pelaksanaan penelitian tindakan kelas ( PTK ) dilakukan sebanyak 2 siklus dan masing-masing siklus dilakukan dengan 1 x pertemuan dan pada setiap akhir siklus dilakukan tes untuk mengetahui hasil belajar siswa.

\section{HASIL DAN PEMBAHASAN}

Siklus I

Proses belajar mengajar menggunakan model pembelajaran problem based learning (PBL), adapun Kriteria Ketuntasan Minimal Mata Pelajaran IPA (KKM=75) diperoleh hasil belajar siswa tertera pada gambar 1 dibawah ini:

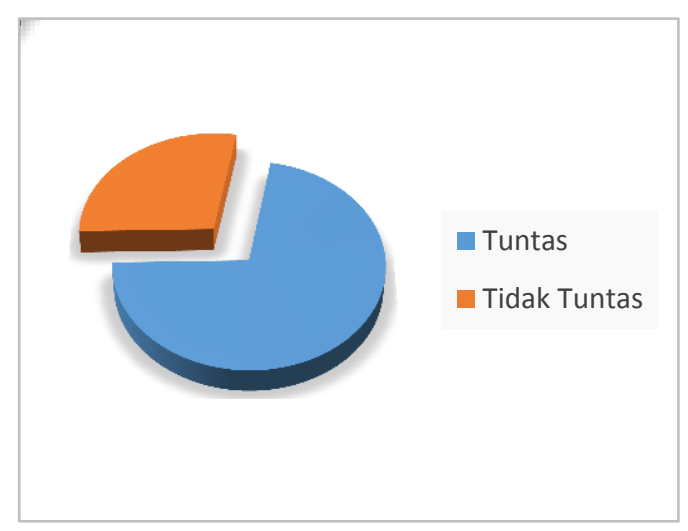

Gambar 1. Hasil Belajar Siklus I

Gambar 1 diatas diperoleh hasil belajar IPA kelas VII SMP Negeri 1 Stabat Tahun Pelajaran 2017/2018, dapat ditarik kesimpulan bahwa pembelajaran dengan menggunakan model pembelajaran Problem Based Learning (PBL) untuk meningkatkan hasil belajar dari 32 orang siswa diperoleh 23 orang yang tuntas dengan $72 \%$ dan 9 orang yang tidak tuntas dengan $28 \%$. Perolehan hasil belajar ini sudah sangat baik, perolehan ini di dukung oleh penerapan pembelajaran Problem Based Learning ( $\mathrm{PBL}$ ) untuk melihat penerapan ini dapat kita lihat hasil observasi penerapan model pembelajaran Problem Based Learning (PBL) yang dilakukan guru diperoleh hasil observasi: 1) pendahuluan, menyampikan deskripsi materi pokok masih belum maksimal dilakukan oleh guru; 2) kegiatan inti, ada 4 hal yang masih belum masksimal yaitu: a) pemberian penguatan, b)pengajuan pertanyaan, c) pemberian contoh/model, d) pola interaksi guru/siswa; 3) untuk penutup sudah baik.

\section{Siklus II}

Perencanaan siklus II berdasarkan kendala dan kelemahan yang ditemukan pada siklus I dari observasi penerapan model pembelajaran Problem Based Learning (PBL), agar kendala dan kelemahan pada siklus I tidak terjadi lagi maka guru berupaya semaksimal mungkin untuk mengontrol kegiatan proses belajar mengajar dan memberikan motivasi kepada siswa. Hasil belajar siswa tertera pada gambar 2 dibawah ini.

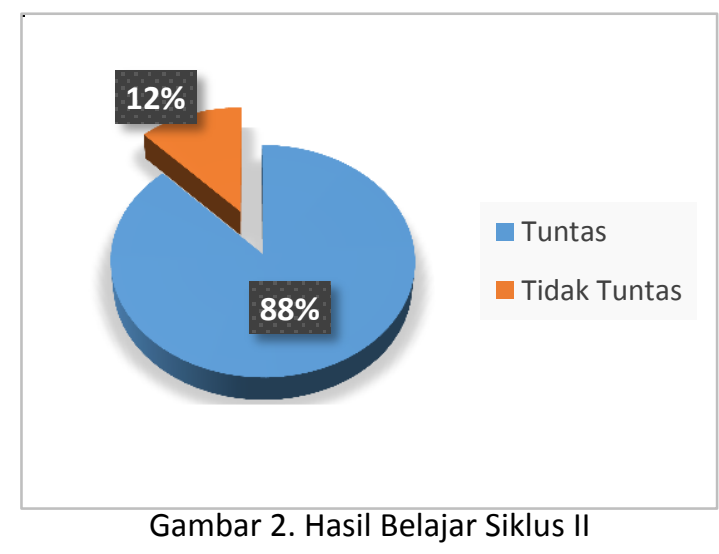

Gambar 2 diatas diperoleh hasil belajar IPA kelas VII SMP Negeri 1 Stabat Tahun Pelajaran 2017/2018, dapat ditarik kesimpulan bahwa pembelajaran dengan menggunakan model pembelajaran Problem Based Learning (PBL) untuk 
meningkatkan hasil belajar dari 32 orang siswa diperoleh 28 orang yang tuntas dengan $88 \%$ dan 4 orang yang tidak tuntas dengan $12 \%$. Perolehan hasil belajar ini sudah sangat baik dan tuntas secara klasikal. Perolehan ini di dukung oleh penerapan pembelajaran Problem Based Learning (PBL) untuk melihat penerapan ini dapat kita lihat observasi, Dari hasil observasi penerapan model pembelajaran Problem Based Learning (PBL) yang dilakukan guru diperoleh hasil observasi: 1) pendahuluan, pada aspek persiapan, pemberian motivasi dan menyampikan tujuan dengan kategori sangat baik; 2) kegiatan inti, ada 5 aspek yang sudah dilakukan guru masuk kategori sangat baik yaitu: Penguasaan materi, urutan penyajian, penggunaan media pembelajaran, pemberian contoh/model, dan pola interaksi guru/siswa; 3) untuk penutup semua aspek masuk kategori sangat baik.

Pada Siklus I penerapan model pembelajaran Problem Based Learning (PBL) memperoleh hasil belajar dari 32 orang siswa diperoleh 23 orang yang tuntas dengan $72 \%$ dan 9 orang yang tidak tuntas dengan $28 \%$, dan hasil pengamatan penerapan model pembelajaran Problem Based Learning (PBL) yang dilakukan guru diperoleh: 1) pendahuluan, menyampikan deskripsi materi pokok masih belum maksimal dilakukan oleh guru; 2) kegiatan inti, ada 4 hal yang masih belum masksimal yaitu: a) pemberian penguatan, b)pengajuan pertanyaan, c) pemberian contoh/model, d) pola interaksi guru/siswa; 3) untuk penutup sudah baik. Hasil refleksi siklus dengan penggunaan model pembembelajaran Problem Based Learning ini siswa dapat beradaptasi dengan baik dalam proses belajar mengajar.

Faktor-faktor yang mempengaruhi keberhasilan penggunaan model pembembelajaran Problem Based Learning dalam meningkatkan hasil belajar walaupun belum tuntas secra klasikal dan kemampuan berpikir kreatif siswa antara lain dari faktor guru, siswa, media yang digunakan, dan ketepatan penggunaan model pembelajaran. Faktor dari guru antara lain: persiapan dalam menyusun perangkat pembelajaran yang terperinci dan lengkap untuk setiap kali pertemuan, pemahaman dari materi metabolisme, penguasaan kelas yang baik sehingga membuat lingkungan belajar yang kondusif dan menyenangkan dan ketepatan dalam melakukan langkah-langkah pembelajaran. Asumsi ini sesuai dengan pendapat (Sardiman, 2011) yang menyatakan bahwa tercapainya tujuan pembelajaran atau hasil pengajaran itu sangat dipengaruhi oleh bagaimana aktivitas siswa dalam belajar.
Pada Siklus II diperoleh hasil belajar dari 32 orang siswa diperoleh 28 orang yang tuntas dengan $88 \%$ dan 4 orang yang tidak tuntas dengan $12 \%$. Perolehan hasil belajar ini sudah sangat baik dan tuntas secara klasikal, dan hasil pengamatan penerapan model pembelajaran Problem Based Learning ( $\mathrm{PBL}$ ) yang dilakukan guru diperoleh: 1) pendahuluan, pada aspek persiapan, pemberian motivasi dan menyampikan tujuan dengan kategori sangat baik; 2) kegiatan inti, ada 5 aspek yang sudah dilakukan guru masuk kategori sangat baik yaitu: Penguasaan materi, urutan penyajian, penggunaan media pembelajaran, pemberian contoh/model, dan pola interaksi guru/siswa; 3) untuk penutup semua aspek masuk kategori sangat baik. Hasil refleksi siklus II ditemukan bahwa model pembelajaran Problem Based Learning meningkatkan hasil belajar dan kemampuan berpikir kreatif dengan alasan materi mudah dipahami dan siswa dapat mengemukakan pendapat sesuai dengan pengetahuan dan pengalamannya, siswa menyatakan pembelajaran menggunakan strategi problem based learning menarik perhatian siswa dengan alasan materi mudah diingat dan siswa menjadi semangat dalam menerima materi pembelajaran. Dapat disimpulkan penerapan model pembelajaran problem based learning dapat meningkatkan hasil belajar IPA siswa kelas VII SMP Negeri 1 Stabat Kab. Langkat TP. 2017/2018. Hal ini sesuai dengan hasil penelitian (Triyuningsih, 2011) yang menunjukkan bahwa model Pembelajaran Berdasarkan Masalah Problem Based Learning dapat meningkatkan kemampuan berpikir kritis siswa pada pelajaran IPA.

\section{KESIMPULAN}

Berdasarkan temuan hasil penelitian dapat ditarik kesimpulan bahwa pada Siklus I penerapan model pembelajaran Problem Based Learning (PBL) memperoleh hasil belajar dari 32 orang siswa diperoleh 23 orang yang tuntas dengan $72 \%$ dan 9 orang yang tidak tuntas dengan $28 \%$. Pada Siklus II diperoleh hasil belajar dari 32 orang siswa diperoleh 28 orang yang tuntas dengan $88 \%$ dan 4 orang yang tidak tuntas dengan $12 \%$. Dapat disimpulkan penerapan model pembelajaran problem based learning dapat meningkatkan hasil belajar IPA siswa kelas VII SMP Negeri 1 Stabat Kab. Langkat TP. 2017/2018.

\section{DAFTAR PUSTAKA}


Halaman : 264-268

Abdullah, Sani Ridwan. 2014. Pembelajaran saintifik untuk kurikulum 2013. Jakarta: Bumi Aksara

Eka Triyuningsih. 2011. Pengaruh Model Pembelajaran Berdasarkan Masalah (Problem Based Learning) terhadap kemampuan berpikir kritis siswa, Jakarta: UIN Syarif Hidayatullah.

Mulyasa. 2008. Menjadi Guru Profesional Menciptakan Pembelajaran Kreatif dan Menyenangkan, Bandung: Remaja Rosda Karya.

Sardiman. 2011. Interaksi Dan Motivasi Belajar Mengajar.Jakarta: PT. Raja Grafindo Persada. 